\title{
Erratum to: AIDS Panic in the Twenty-First Century: The Tenuous Legal Status of HIV-Positive Persons in America
}

\author{
Richard G. Cockerill • Lance Wahlert
}

Published online: 12 April 2016

(C) Journal of Bioethical Inquiry Pty Ltd. 2016

Erratum to: Bioethical Inquiry (2016)

DOI 10.1007/s11673-015-9653-5

The initial is missing from the first author name and should read Richard G. Cockerill.

The online version of the original article can be found at http://dx. doi.org/10.1007/s11673-015-9653-5.

R. G. Cockerill $(\bowtie)$

Mayo Medical School, Mayo Clinic College of Medicine, 200 1st St SW, Rochester, MN 55905, USA

e-mail: rcockerill@mednet.ucla.edu

L. Wahlert

Perelman School of Medicine, Department of Medical Ethics and Health Policy, University of Pennsylvania, 415 Curie Blvd,

Philadelphia, PA 19104, USA 